Portland State University

PDXScholar

6-16-2021

\title{
Colorful, Weird, and Wonderful: the Influences of Subculture on the Fashion of the 1960s
}

Gianna M. Zanzi

Portland State University

Follow this and additional works at: https://pdxscholar.library.pdx.edu/honorstheses

Part of the Fashion Design Commons

Let us know how access to this document benefits you.

\section{Recommended Citation}

Zanzi, Gianna M., "Colorful, Weird, and Wonderful: the Influences of Subculture on the Fashion of the 1960s" (2021). University Honors Theses. Paper 1080.

https://doi.org/10.15760/honors.1107

This Thesis is brought to you for free and open access. It has been accepted for inclusion in University Honors Theses by an authorized administrator of PDXScholar. Please contact us if we can make this document more accessible: pdxscholar@pdx.edu. 


\title{
COLORFUL, WEIRD, AND WONDERFUL: \\ THE INFLUENCES OF SUBCULTURE ON THE FASHION OF THE 1960s \\ by \\ GiANNA ZaNZI
}

\author{
An undergraduate honors thesis submitted in fulfillment of the \\ requirements for the degree of \\ Bachelor of Fine Arts \\ in \\ UNIVERSITY HONORS \\ and \\ GraPhIC DESIGN
}

Thesis Advisor

Meredith JAmes, M.F.A.

Portland State University

2021 


\section{COLORFUL, WEIRD, AND WONDERFUL * GIANNA ZANZI}

\section{Abstract}

In this paper, I attempt to examine the fashion of three dominant subcultures within the American Counterculture movement of the 1960s—-the Youthquakers, Mods, and Hippies-before discussing my project that was synthesized from this research; three outfits, one representing each subculture, that I had sewn using vintage and vintage-inspired patterns, fabrics, and notions. While I myself was not alive during the 1960s, my interest in the aesthetics associated with the decade were my motivation for trying my hand at creating period-accurate clothing using techniques and materials that would have also been used at this time. This essay is the documentation of the process I had undergone in an attempt to answer the question, "What were the influences behind the Youthquake, Mod, and Hippie movements, and can the unique clothing of each of these subcultures still be faithfully replicated today?"

\section{INTRODUCTION}

To fashion designer and curator Michael Cepress, the 1960s and 70s were "....a time when self-sufficiency and self-expression became acts of resistance. The idea... was to take what you had, and let it out, literally wear it on your sleeve. There is only one you so why not celebrate that in whatever colorful, weird, and wonderful, way?" (Newell-Hanson, 2017, para. 8). 1960 all the way through to 1969-a period of ten landmark years that held within its bookends: growing political unrest, the birth of a war, the resurgence of a fight for equal rights between races and genders, the genesis of many important subcultures, and a shift in increasing consumerism that would soon become the new standard-and this was just within the United States alone (Public Broadcasting Service, 2005). Continuously evolving in the time between all of these happenings, fashion was directly being influenced by these current events, with clothing pieces serving as timestamps to direct moments in history, like a fashionable call and response.

Fashion, though, has always served an important role in social anthropology, as going all the way back to the earliest evidence of clothing from the Stone Age, it serves as a way for historians to learn about aspects of earlier societies, like where they were located, what the clothing was made from, what job they might have had, or what their societal standing might have been. As much as we might like to assume that these insights are only reserved for antiquated societies since our clothing styles and manufacturing processes have changed so much over time, the truth is that the clothing that we all wear today still tells so much about us (Davenport, 2020). For instance, our clothing today might reveal that cotton and synthetic materials are currently the most commonly-used fibers in clothing manufacturing, and that our fashion trends have become more globally-influenced as a result of the internet. But what can be said for fashion in a decade like the 1960s, which witnessed such rapid changes in clothing styles, materials, and manufacturing?

In this paper, I attempt to delve deep into three important fashion subcultures within the United States-the clothing of the Youthquakers, Mods, and Hippies-that each emerged out of the 1960s as a response to the rise of cultural globalization (through the increased availability of technologies like travel, music, television and film, etc.), and to the nation's politics. I begin by first explaining the significance and history behind each culture, before delving into why I chose to create each outfit using period-correct fabrics and methods, then diving into the construction process, and what was learned from the project. This thesis 


\section{COLORFUL, WEIRD, AND WONDERFUL * GIANNA ZANZI}

was born from a genuine love of the aesthetics of the 1960s, and a curiosity and desire to learn more about the cultural significance behind the clothing of the period.

\section{The Subcultures}

The term, "Youthquake" was first coined by American Vogue's then editor-in-chief, Diana Vreeland, in 1965 to emphasize the dramatic shift towards youth-centered media and culture that was happening across the globe (Görkem, 2018). Youthquake fashion quickly took hold over the teen clothing market, as it felt a bit more hip and lively than the earlier Mod fashion, but wasn't quite as avant garde as some of the bespoke and gaudy clothes associated with Psychedelic fashion. Youthquake clothes were highly commercial-having been inspired by Mary Quant's mini skirt and the new and innovative Day-glo fabrics that popped off the clothing rack (Victoria \& Albert Museum, 2019). The 60s marked the first decade where clothing was directly marketed to teens, and Youthquake fashion and its a-line silhouettes sold well. With the demand for the clothing continuously growing, and the shift towards inexpensive-to-produce and quick-to-manufacture plastic polymers and synthetics in everyday items, this led to innovations like polyester fabric, plastic jewelry and hair accessories, and the brief trend of disposable paper dresses. Although Youthquake fashion did take the US by storm, its origins are tied to London's famous Carnaby Street, where stores like Lady Jane, Carnaby Girl, Paraphernalia, and Tre Camp ruled the scene from the movement's beginning in the mid-60s to its decline at the end of the decade. Those closely associated with the "Youthquake look" were celebrities like Twiggy, Edie Sedgwick, and Jean Shrimpton. In many ways, Youthquake fashion is the starting point to this thesis, as it took direct inspiration from Mod fashion, and birthed the iconic Hippie fashion aesthetic, which was a direct criticism of the new standard of fast fashion within clothing manufacturing as well as commercialism's permeation into youth culture.

The next subculture in the sequence are the Mods. Mod fashion was most popular in the early-to-mid-60s, and its iconic clean lines and minimalist garments were a result of the public's continued fascination with space age aesthetics, inspired by the technological duel between Russia and the US to see who would make it to the Moon first (Casburn, n.d.). Shortened from the word "modern," Mod fashion also originated in London, this time around the King's Road area, not too far from Carnaby Street, and crossed the pond to the US during the "British Invasion" of popular culture from the UK, which stemmed from events like the Beatles' first performance on the Ed Sullivan Show in 1964 (Hall, 2014, p. 69). Favoring either monochromatic outfits in black and white, or the triad of primary colors, Mod clothing tended to be quite minimal and refined, sticking to the popular mini skirt and a-line dress trend, too. The fabrics tended to be the star of these outfits, with structured skirt suits and pinafores-apron-like dresses-in soft wools and baubled bouclés bringing in visual interest through its thoughtful use of texture. In the clothes that did feature patterned fabrics, they were almost always very linear and geometric, as well. Unconventional materials like transparent vinyl and clothes made from chainmailed pieces of metal graced the pages of high fashion magazines as being the most innovative and cutting-edge examples of Mod fashion, and bubbled variations on the pillbox hat and large round and rectangular sunglasses were quite common accessories. Designers like Pierre Cardin, Paco Rabanne, and Andre Courreges translated the world's fixation with futurism at the time into wearable art, and although this subculture was short lived, to this 


\section{COLORFUL, WEIRD, AND WONDERFUL * GIANNA ZANZI}

day it's still one of the most recognizable movements within 1960s fashion (Zimmermann, 2013).

The Hippie movement was one of-if not the most-iconic subcultures of the decade, but time-wise, was a flash in the pan, lasting from about 1965-1968. By the time the Hippie movement had gained enough traction to become popular, it was already over, with the majority of its original movers and shakers moving away from San Francisco's Haight Ashbury district once the Summer of Love in 1967 had turned the neighborhood into a must-see tourist attraction. A subculture that criticised capitalism and consumerism and society's preoccupation with war, Hippies celebrated "radical thought," placing value in creative pursuits and a backto-basics philosophy that sparked an uptick in homesteading across the US (Brown, 2011, p. 205). The earthy and bespoke fashion that we so-closely associate with this movement was spurred by the influx of artists that flocked to San Francisco during this period, with fiber artists and fashion designers like Kaisik Wong, Birgitta Bjerke, Richard "Scrumbly" Koldewyn, Norman Stubbs of the infamous East West Musical Instruments Company, and the Merry Pranksters paving the way (Newell-Hanson, 2017). After the Maharishi Mahesh Yogi's meeting with the Beatles in 1968, there was a growing interest around the world in transcendental meditation, sparked by the Maharishi teachings. This led to a broader interest in the culture and aesthetics of India, which can also be seen reflected in some Hippie clothing (Koppel, 2008). Unique to its locale, it was a time and place where anything went, but despite the few that took the Hippie fashion to the extreme, most people that subscribed to the Hippie philosophy weren't decked out to the nines in psychedelic jester costumes and crocheted suits, but dressed in more typical street clothes or favored vintage and secondhand fashion, as it still veered away from the popular styles at the time and was less expensive. These styles can be seen in the 1967 CBS documentary, The Hippie Temptation. Suffice to say, Hippie fashion was not one singular clothing style or iconic silhouette, but was a means of expression-a chance to wear your feelings, interests, political sentiments, anything - on your sleeve for the world to see.

\section{The Project}

Each of these subcultures is one that I chose to represent in this project because of its influence and longevity in the fashion world. The silhouettes, fabric patterns, key figures, accessories, etc., associated with Youthquake, Mod, and Hippie fashion are still a very relevant source of inspiration for current designers, for as much as the clothing from this period stands out as being uniquely retro, aspects from these subcultures, like a-line silhouettes, the mini skirt, and neon fabric dye have stood the test of time and are still regularly worn today.

Going into this thesis project, I knew that the end goal would be to reproduce three outfits-one from each subculture-as faithfully as I could, using either true vintage fabric and notions, like buttons and zippers, from the 1960s or modern fabric that was made of the correct materials and had the right texture or patterns; actual 1960s sewing patterns from my collection; and lastly, sewing each garment together following the vintage pattern instructions to a tee. I would also make an accompanying booklet for the three outfits that detailed the thought process behind each outfit as well as how each piece was constructed. These steps that I had prescribed to myself were set in place in an effort to create these three outfits as period-accurately as possible, as the goal for this project was not just to sew three outfits to resemble three unique subcultures, but to also gain insight into what those making their own 


\section{COLORFUL, WEIRD, AND WONDERFUL * GIANNA ZANZI}

clothes during this time might also have similarly experienced, which I wouldn't have been able to glean otherwise.

The process of sewing one's own clothes today in the US is largely a relic of a bygone era, where nowadays buying new clothing in stores or online is the standard, but is also one of the largest resource-intensive and polluting industries worldwide, and is a practice that is severely unsustainable as it currently stands (Gunner, 2019). Ever since the precedent had been set in the 1960s that fashion would be conscientiously marketed towards men, women, and children, the prevalence of handmade clothing has been on the decline as the demand for fashionable clothing has continued to grow exponentially to the frenetic rate that it's at today, where fashion trends are ever changing due to social media, and clothing manufacturers are hard pressed to keep up (Michaela \& Orna, 2015). Current teenagers and young adults, however, have been returning to hobbies and professions like jewelry making, ceramics, and sewing in recent years due to the influence of apps like Instagram and Tik Tok, and the viability of being able to live off of the earnings through selling their wares on websites like Etsy and Depop (Greenwood, 2021). This needed to be acknowledged, as I myself fall within this category after picking up an interest in sewing in middle school after seeing people's clothing that they had made online, and dusting off my Mom's old sewing machine and giving it a try myself. It was through the internet that I was able to find communities online that shared an interest in vintage and historical clothing, and is where I first started to do my own research on the fashion of the 1960s after seeing images from books like Native Funk and Flash by Alexandra Jacopetti shared on Tumblr and Pinterest. That was the genesis of this project, and my want to learn more about the distinct styles of the 60 s was my motivation. 


\section{Youthquake Fashion Moodboard}
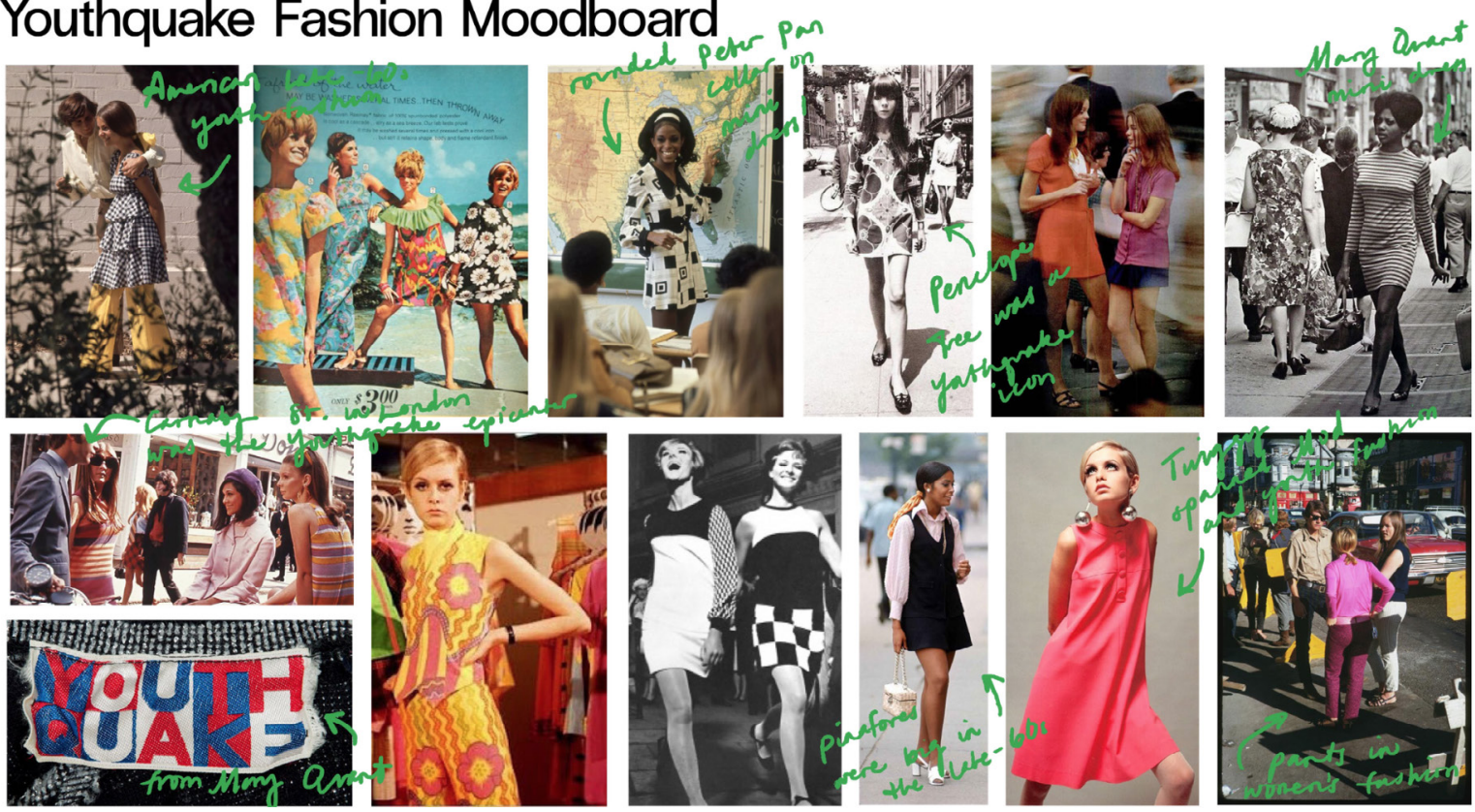

fig. 1, Youthquake Moodboard, Gianna Zanzi, 2020
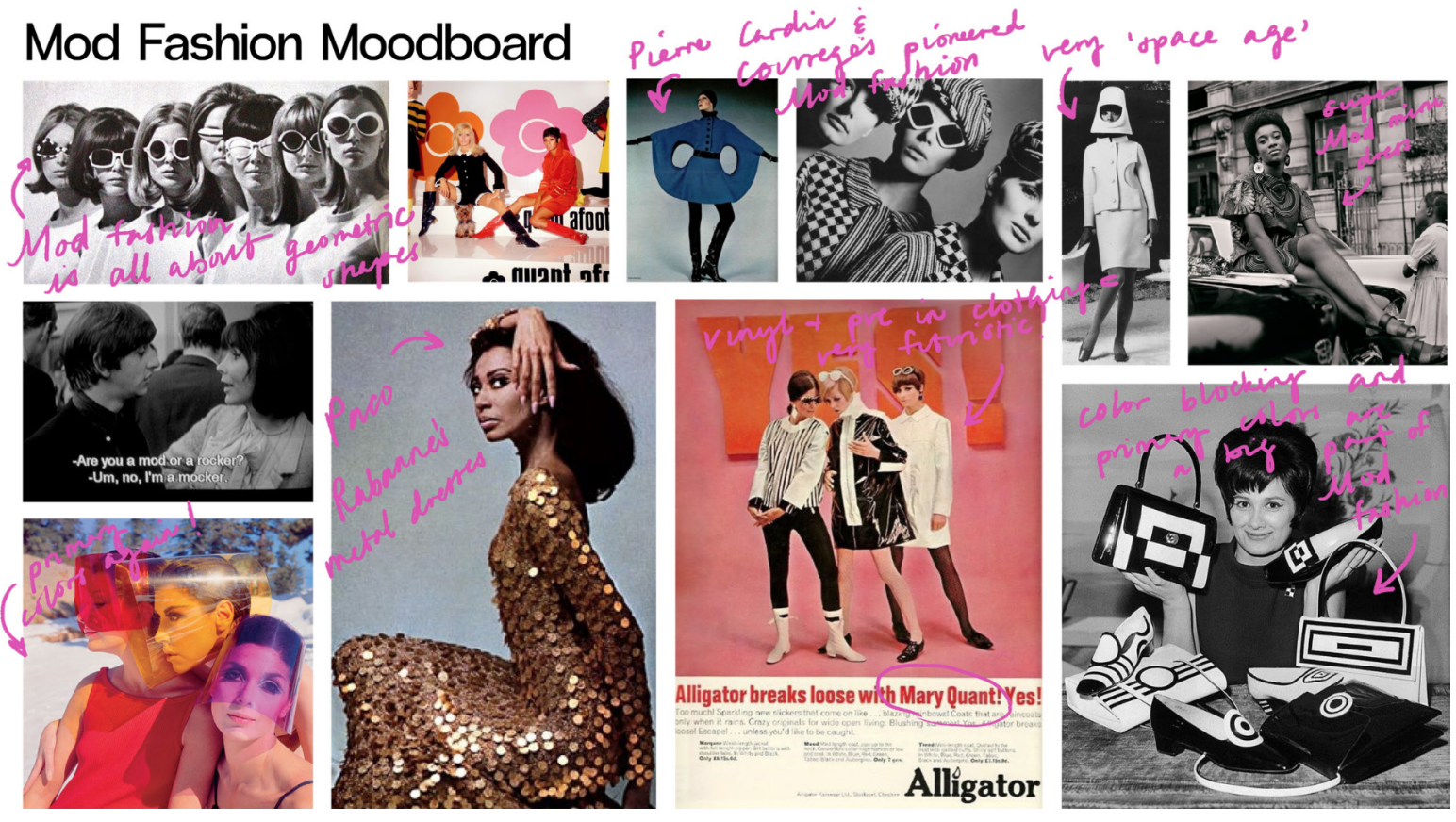

fig. 2, Mod Moodboard, Gianna Zanzi, 2020 
Hippie Fashion Moodboard
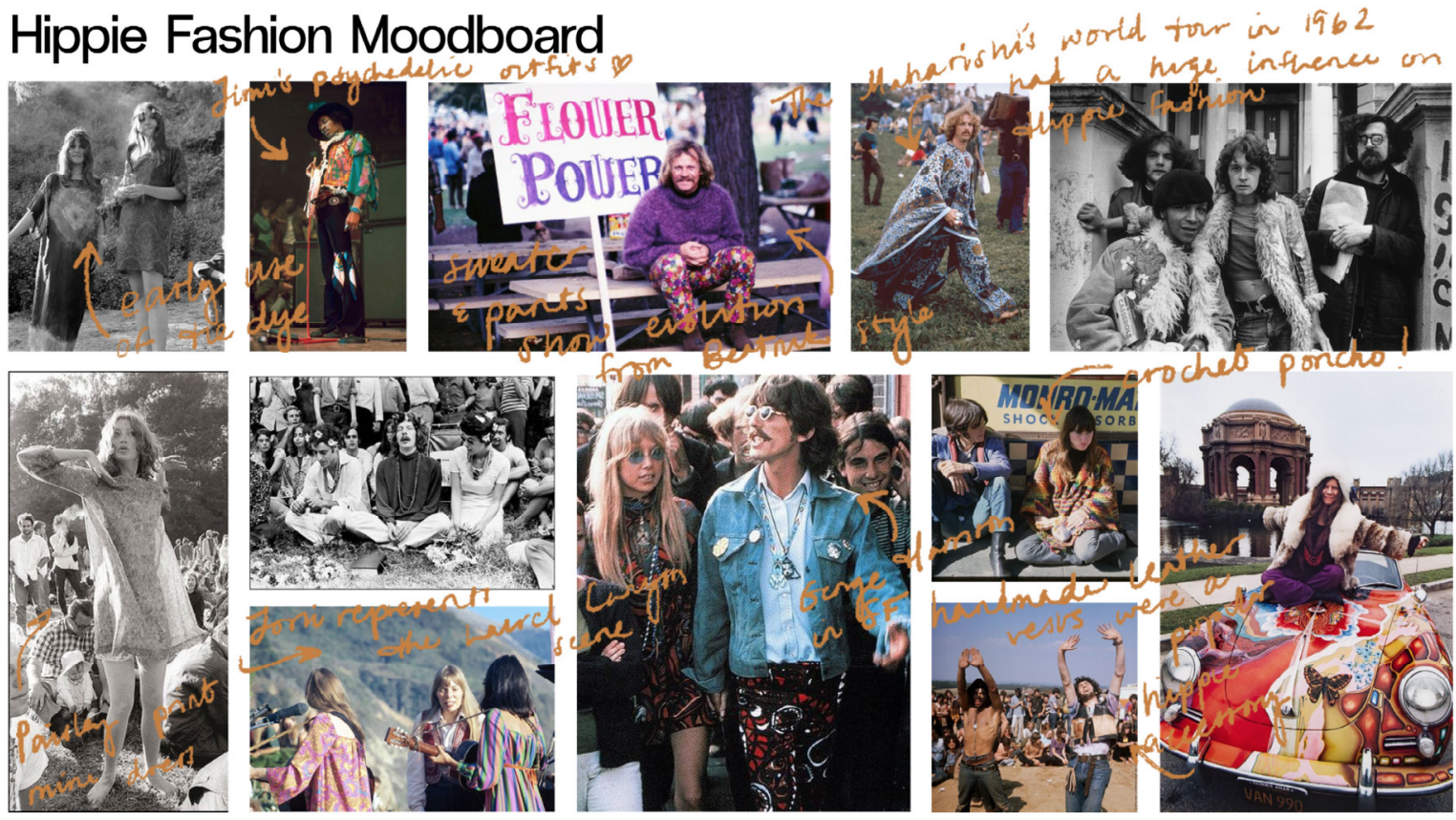

fig. 3, Hippie Moodboard, Gianna Zanzi, 2020 


\section{COLORFUL, WEIRD, AND WONDERFUL * GIANNA ZANZI}

\section{The Construction}

The Youthquake dress was the first of the three outfits that I had began construction on, as it was the only one where I already had the materials for it on-hand, and its a-line silhouette was one that I had thought would be a good place to start and ease me into the project to get my bearings before attempting more complicated patterns for the other two. I had chosen a vintage mini a-line dress pattern that was very referential of Mary Quant's popular silhouettes, and the fabric that I used was true vintage from-the1960s that I had sourced from Portland's own SCRAP secondhand art store the term before, as it had the perfect pink, yellow, orange, olive, and blue Dayglo flower pattern to represent the liveliness and energy of the Youthquakers. At $13 / 8$ yards wide, the fabric was the exact amount that I had needed in order to size up my vintage size 10 pattern into a vintage size 12 , and when I gingerly unfolded the piece of fabric for the first time, it revealed a panel of the same pattern at the bottom selvedge edge that ran perpendicular to the horizontal stripes, and created a lovely effect at the hem of the finished dress.

When it came to the construction of each of these dresses, I tried my best to follow the now nearly 60-year-old instructions to a tee, which led me to overlocking each of my pattern pieces before I could start construction on the dress. The overlock stitch, with the help of the overlock foot, is a stitch on some sewing machines that encases the raw edge of the fabric in thread so that when the finished garment is washed, the threads don't have the chance to unravel, making each project that it's used on more durable over time. Once each piece of the pattern had been overlocked, I was then able to go ahead with the construction process, adding a vintage plastic zipper to the back of the dress, tacking down the inner facings around the neck and arm holes by hand with small whipstitches, which finished the first of three looks. For the photos, I also wanted to keep the styling of each outfit true to its representative subculture, so for this a-line dress, I paired it with my black patent loafers that have a small heel, and followed a tutorial for the 60s cut crease eye makeup, trying to reference the 60 s youth icon, Twiggy, and put my hair up into a mild 60s bouffant. 


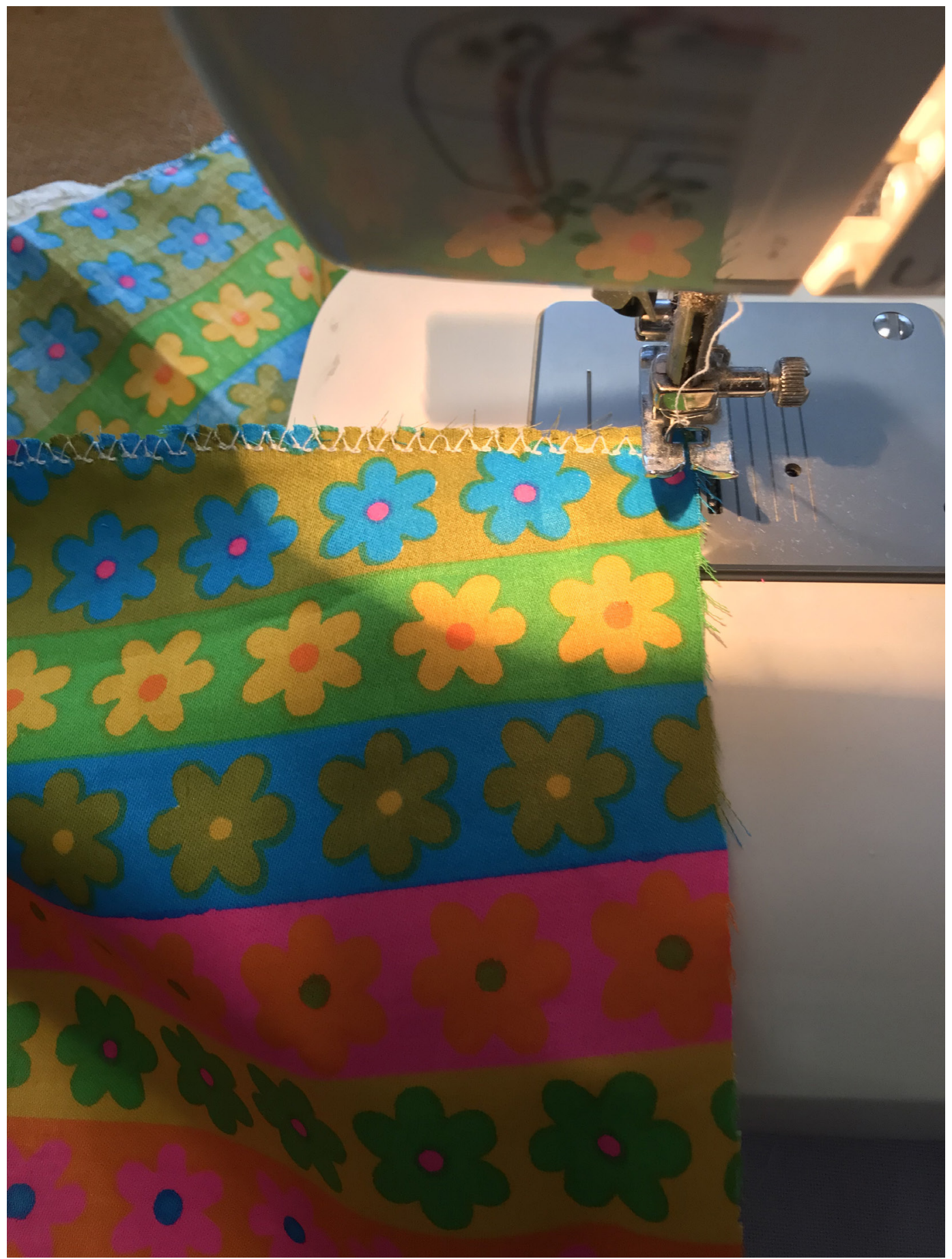

fig. 4, The Overlocking stitch. 
COLORFUL, WEIRD, AND WONDERFUL * GIANNA ZANZI

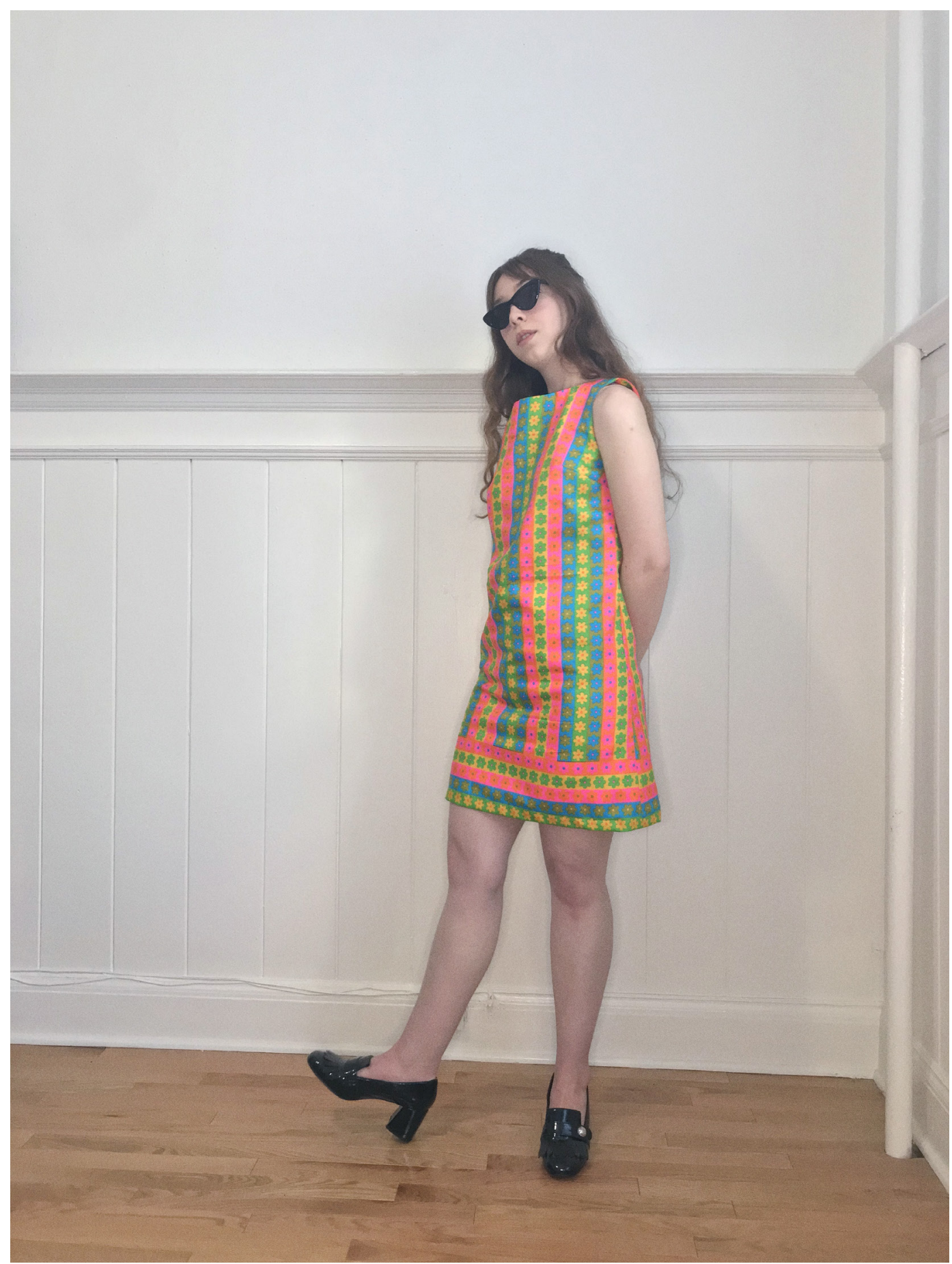

fig. 5, Youthquake Dress, front, Gianna Zanzi, 2021 
COLORFUL, WEIRD, AND WONDERFUL * GIANNA ZANZI

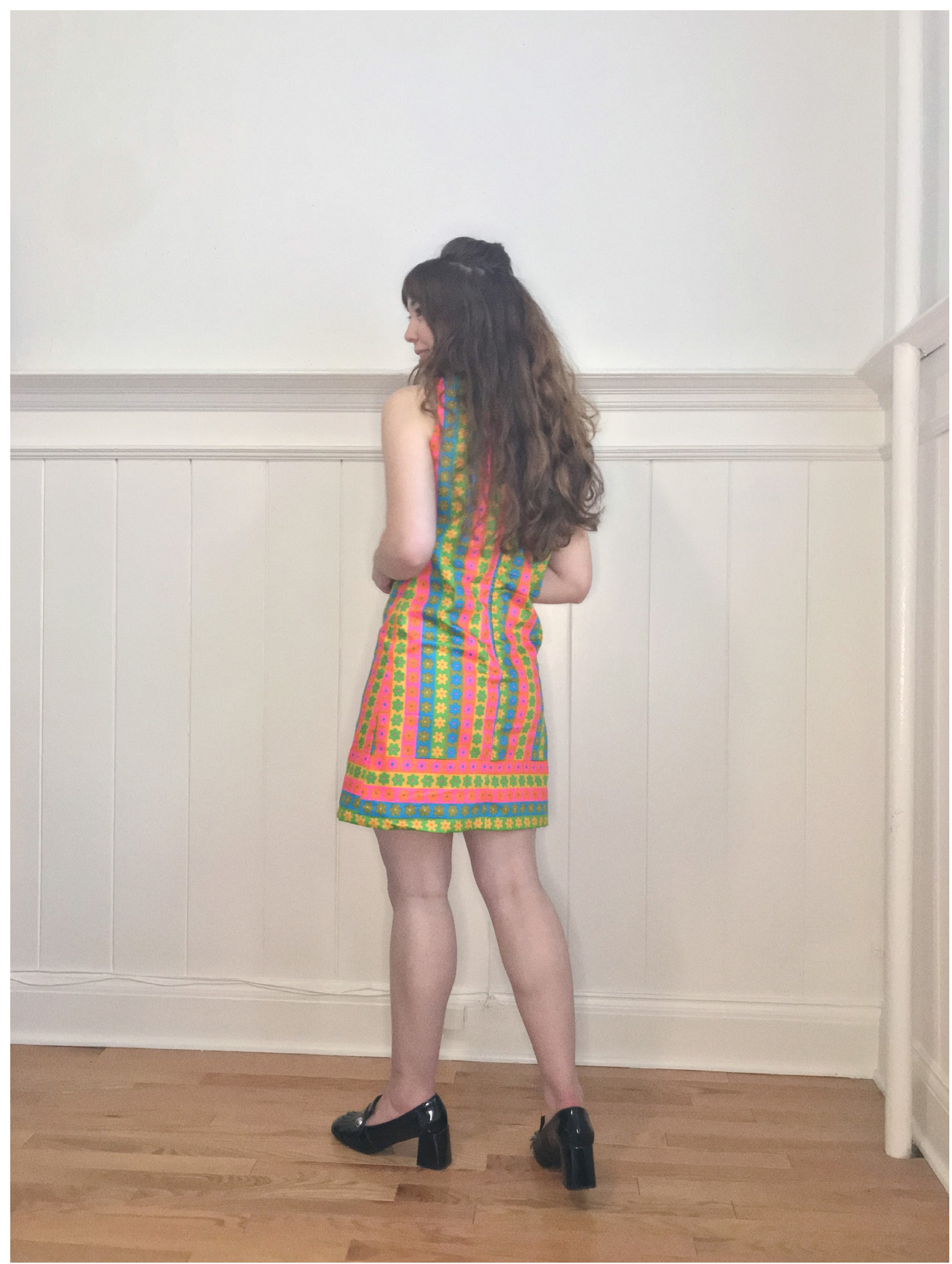

fig. 6, Youthquake Dress, back, Gianna Zanzi, 2021 


\section{COLORFUL, WEIRD, AND WONDERFUL * GIANNA ZANZI}

For the second outfit, I chose a vintage two piece pattern from my vintage pattern stash; one with an a-line mini pinafore and interesting bishop sleeve blouse with a funnel neck. I had wanted to go with a matching set for this outfit, as I didn't want to construct just a single dress to represent each culture, considering that there were so many more varied and intriguing silhouettes and clothing pieces that could be represented from 60s fashion, and after putting together a Mod moodboard, thought that this would be the perfect opportunity to do a coordinated two-piece look inspired by the skirt suits that were fashionable within the Mod community. I went with a monochromatic black and white color palette for this outfit, as well, and after looking around in SCRAP again and online for more 1960s fabric and coming up empty-handed, I turned to Mood Fabric online, and found a white boiled wool there for the pinafore that would be the focus of the outfit with it's beautiful bouclé texture.

I once again used the overlocking stitch on all of my pattern pieces before starting the construction process, and was surprised by how little steps there were to the outfit. Using the boiled wool for the pinafore had a bit of a learning curve, as I had never used it before, and had read online to only iron it on the lowest setting if absolutely necessary. The only issue in the process that I had run into with the wool was after I had started to lay it out to cut out the pattern pieces, and realized that it was a bit more sheer than I had anticipated, and would need to be lined with a matching white cotton that I had. This meant that I had to improvise a bit with the pattern instructions to accommodate the changes, but not alter the design. The shirt came together without any hitches, and was sewn out of a white cotton that had a raised, waffled texture to it to contrast the texture of the pinafore. The facings on the blouse were also tacked down by hand, and the last step was adding two decorative buttons from the 60 s that I had found secondhand to the back of the straps on the pinafore. This outfit was styled with the same black loafers, a pair of black tights, a black wide headband, and my Mod sunglasses for the photos. 
COLORFUL, WEIRD, AND WONDERFUL * GIANNA ZANZI

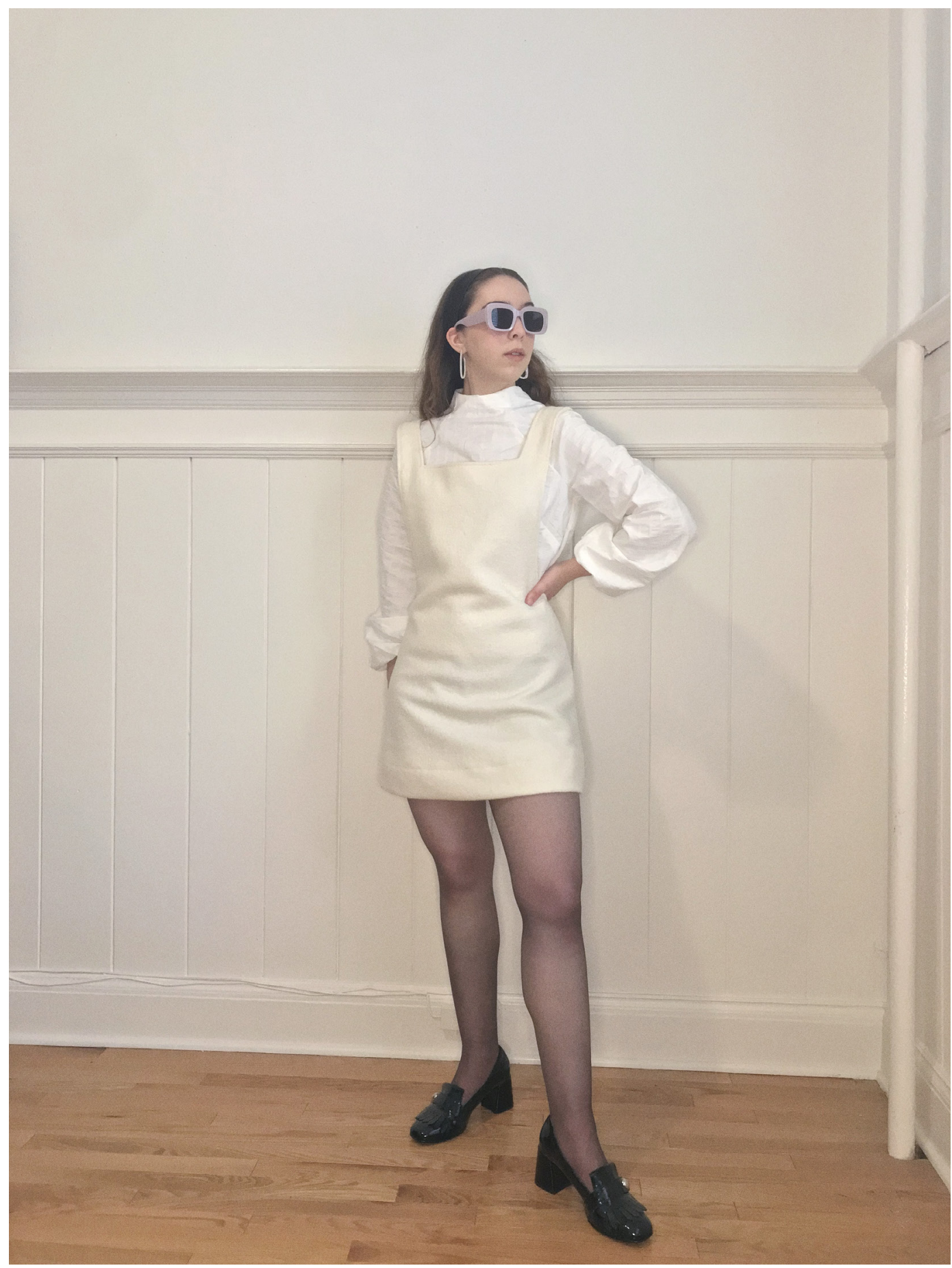

fig. 7, Mod Dress \& Pinafore, front, Gianna Zanzi, 2021 
COLORFUL, WEIRD, AND WONDERFUL * GIANNA ZANZI

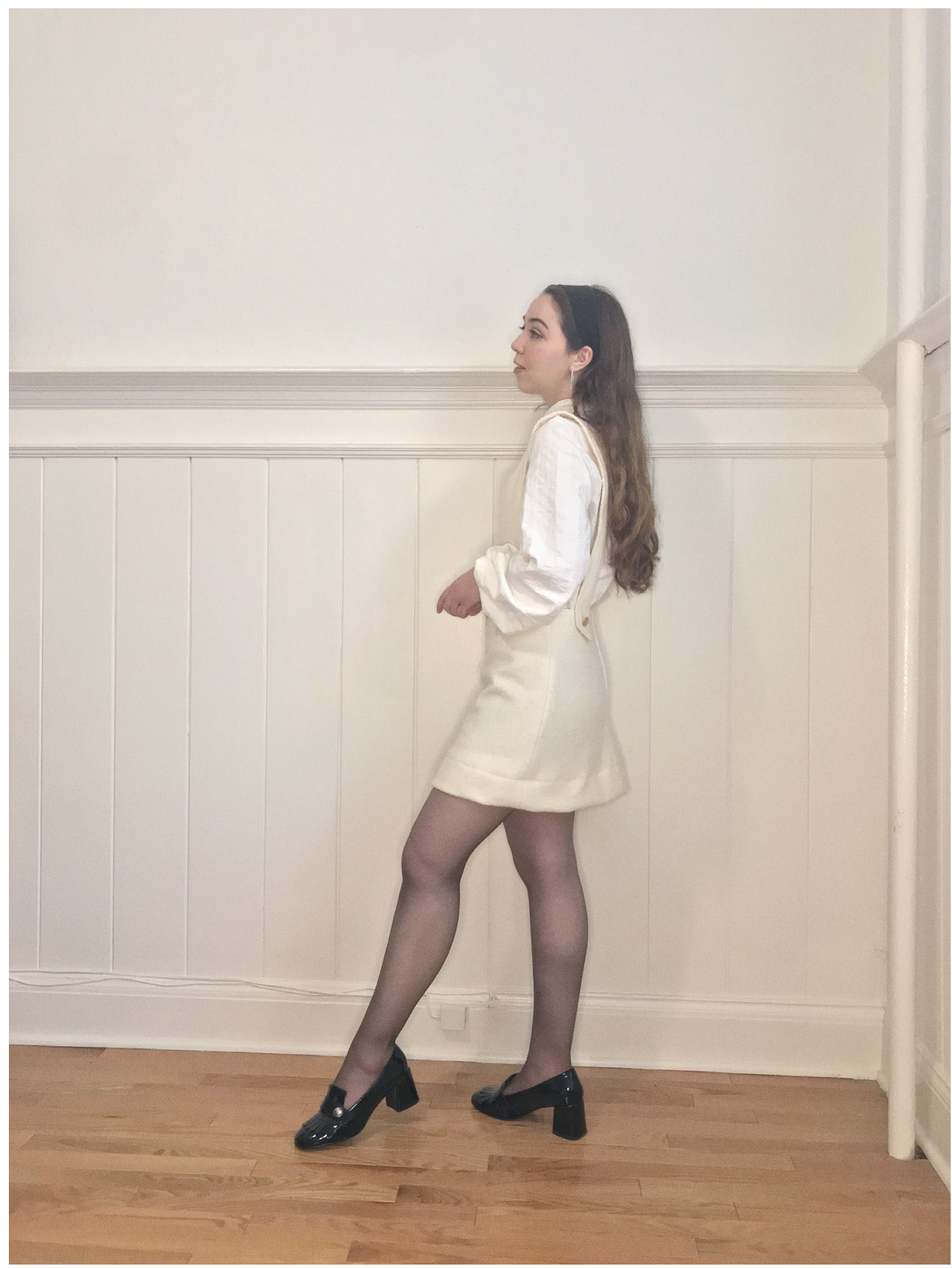

fig. 8, Mod Dress \& Pinafore, back, Gianna Zanzi, 2021 


\section{COLORFUL, WEIRD, AND WONDERFUL * GIANNA ZANZI}

I had saved my trickiest pattern for last-the Hippie dress. Modified from a wedding dress pattern from 1969, the dress boasted bold Renaissance sleeves and an empire waistlineand I thought that with the right fabric choicecould be reminiscent of an outfit that Pattie Boyd had worn on her and George Harrison's first visit to Haight Ashbury in San Francisco in 1967 (Miller, 2017).

I started again by using the overlock stitch on all of the raw edges of the pattern pieces before starting the construction process. The fabric that I had chosen was also from the same Mood Fabric order, and was an avocado green and brown tie dye on a heavy cotton, taking inspiration from the early pre-rainbow use-cases of tie dye generated from Haight Ashbury's Free Store (Time, 1970). The fabric was definitely a bold choice, but I had liked that it was an earthier tie dye which was more true to the time period, as the rainbow tie dye that we now closely associate with Hippies wasn't commonly used yet. The only issue that I had run into on this outfit was that the very first pattern piece, A: the front of the bodice, was nowhere to be found. I had used the pattern pieces from the back of the bodice to transfer the markings and shoulder width, and had used the front facing piece to get the neckline, and then estimated where the darts would go. After making a mockup out of cotton muslin quickly, I was able to make a few small changes and get the construction process going again. I had also cropped the dress into a mini skirt, as the original pattern had called for a floorlength skirt, but a dress with an empire waist and long skirt would have been too formal of a silhouette for this subculture. The last pieces that I had constructed were the sleeves, which were a construction anomaly. In total, just those two sleeves used up over one entire spool of thread-over $100 \mathrm{yds}-$ and one yard of elastic to create those three sections going up each sleeve. Similar to the previous two outfits, the neck facing was tacked to the inside seams by hand, completing the final outfit! For these photos, I styled the dress with my lace up sandals that were the closest thing I had to the gladiator sandals that Pattie Boyd wore in her outfit, and left my hair down without any styling. And just like that-as quickly as the project began - my three outfits were finished and all sewn. 


\section{COLORFUL, WEIRD, AND WONDERFUL * GIANNA ZANZI}

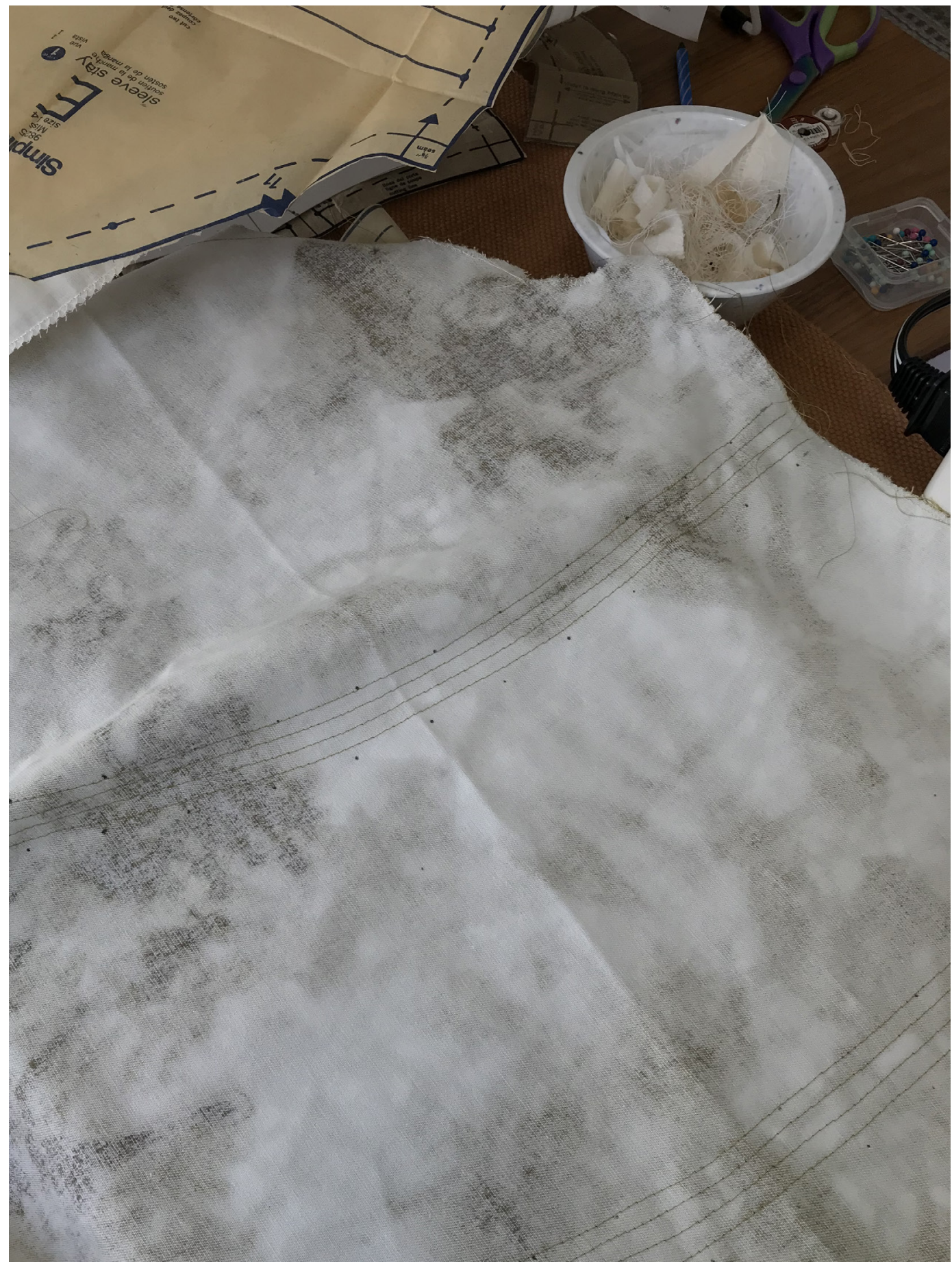

fig. 9, Inside of Hippie Dress sleeve before gathering. 
COLORFUL, WEIRD, AND WONDERFUL * GIANNA ZANZI

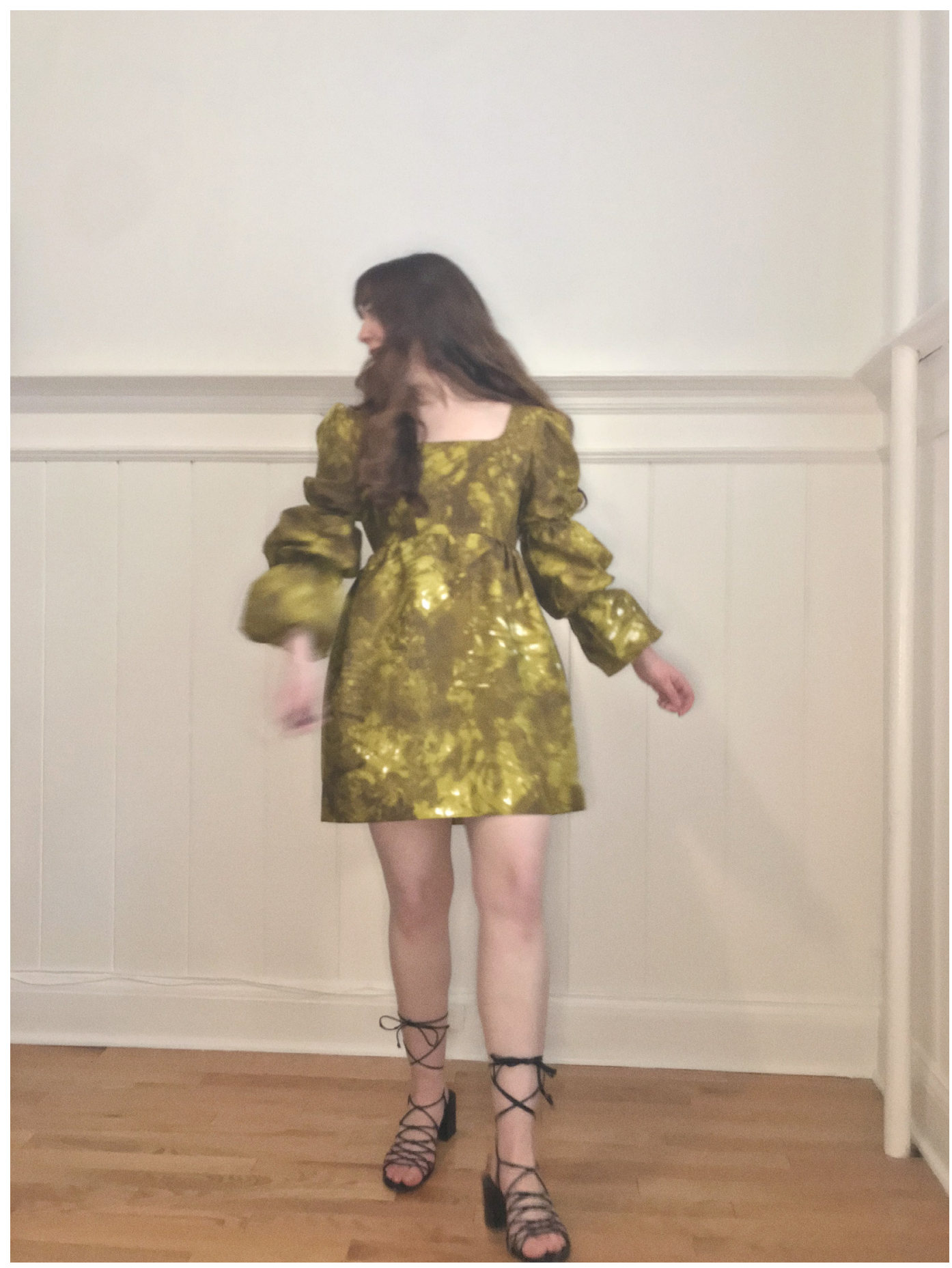

fig. 10, Hippie Dress, front, Gianna Zanzi, 2021 
COLORFUL, WEIRD, AND WONDERFUL * GIANNA ZANZI

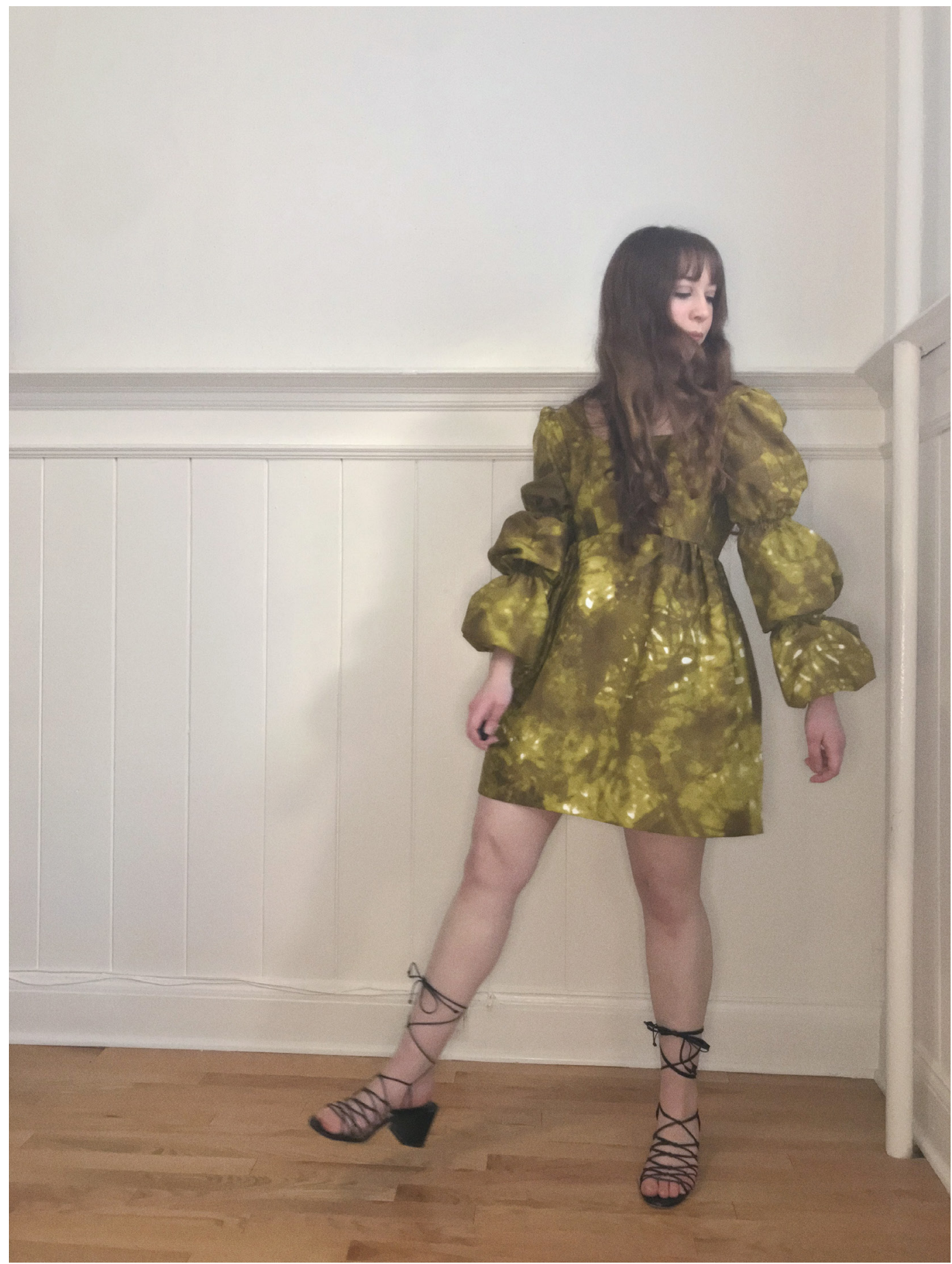

fig. 11, Hippie Dress, side, Gianna Zanzi, 2021 


\section{COLORFUL, WEIRD, AND WONDERFUL * GIANNA ZANZI}

\section{Conclusion}

Now that I've had time to reflect on the process of sewing together each of these outfits, I've thought about what went well in the process, what I had learned, and realized where I went wrong in some spots. For example, I really enjoyed learning how to use the overlocking stitch and machine foot for this project, as it was something that I had never attempted before, but can now definitely see myself using on sewn garments in the future, as it will really make them more durable, with the tradeoff that it does take quite some time to complete. I'm also very happy with the final silhouettes and fabrics of each of the outfits, as I feel that they are a true representation of what would have been worn in the 1960s, and can be comfortably identified and placed within each subculture that they represent. Seeing the reactions from family members who had experienced the 60 s firsthand, as well as friends who also have an interest in the aesthetics of the decade is what made this project so special to me, as it was heartwarming to see the emotional impact and nostalgia that the clothing carried for some.

In terms of areas of improvement, I realized after I had made the outfits, that of the four zippers that I had used in total for this project, two-the ones for my Mod blouse and Hippie dress-are invisible zippers, which were not commercially available until 1968 (Dean, 2010). This is cutting it close in terms of accuracy, and in hindsight, I would have changed them for normal, metal zippers if I were to make these outfits again. Another step that I would revisit would be the handsewn facings on the inside of the garments, as to save on time, I just tacked the facings to the inside seams instead of sewing all sides down. If I do go on to wear any of these pieces again, it might be worthwhile to go back in and do, as that's more of a permanent solution to keeping the facings held in place.
Overall, I'm quite proud of this project, as it pushed me outside of my usual comfort zone for my sewing projects, and helped me to gain some insight into just how much care, time, and attention was put into clothing like this, giving me the confidence to continue researching retro clothing beyond just the scope of this project, as well as sewing more vintage patterns in the future. It was also incredible to see the impact that culture and current events have on fashion, as with this project, I had the fortune of being able to research and reflect on a past decade rich with lasting impact, leading me to wonder what future researchers will be able to glean from the fashion of today? 


\section{COLORFUL, WEIRD, AND WONDERFUL * GIANNA ZANZI}

\section{REFERENCE LIST}

[1.] Brown, D. (2011). Chapter 7: Back to the garden - The 1970s. Back to the land: the enduring dream of self-sufficiency in modern America (p. 205). essay, University of Wisconsin Press.

[2.] Casburn, M. M. (n.d.). A concise history of the British Mod movement. The Greater Bay Area Costumers Guild. http://www.gbacg.org/costume-resources/original/ articles/mods.pdf.

[3.] Columbia Broadcasting System, Inc. (1967). The Hippie Temptation. New York.

[4.] Davenport, E. (2020). The anthropology of dress and fashion: A reader. Dress: The Journal of the Costume Society of America, 46(1), 67-69. https://doi.org/10.1080/ 03612112.2019.1707990

[5.] Dean, Ninette. (2010, May 3). The up and down history of the zipper. Smithsonian Libraries / Unbound. blog.library.si.edu/blog/2010/05/03/the-up-andown-history-of-the-zipper/\#.YFKIZLRKils.

[6.] Görkem, Şenay. (2018). An inquiry on the notion of Youthquake: Initiation, management and media coverage, 1st International Conference on New Approaches in Social Science and Humanities, Antalya, Turkey, April 20-22, 2018.

[7.] Greenwood, D. (2021, May 6). It's official: the pandemic birthed the 'sew bro'. I-D. https://i-d.vice.com/en_uk/article/v7eepj/gen-z-sewing-quilting-tiktok-sew-bros.

[8.] Gunner, A. (2019). Fast fashion and its impact on the environment. Logistics \& Transport Focus, 21(5), 40-41. http://web.b.ebscohost.com.proxy.lib. pdx.edu/ehost/detail/detail?vid=0\&amp;sid=6f04aab7-dcaf-4056-8b25-8b0d f17b0a2d\%40sessionmgr 103\&amp;bdata=JnNpdGU9ZWhvc3QtbGl2ZQ\%3d\%3d \#db=buh\&amp;AN=136195776.

[9.] Hall, M. K. (2014). Chapter 3: The Beatles and the British invasion. The emergence of rock and roll: Music and the rise of American youth culture (p. 69). essay, Taylor \& Francis.

[10.] Jacopetti, A., \& Wainwright, J. (2013). Native funk \& flash: An emerging folk art. Trafford Publishing. https://www.google.com/books/edition/Native_Funk_Flash/ IYAf9RG9GPkC?hl=en\&amp;gbpv=1\&amp;printsec=frontcover.

[11.] Koppel, L. (2008, February 6). Maharishi Mahesh Yogi, spiritual leader, dies. The New York Times. https://www.nytimes.com/2008/02/06/world/asia/06maha rishi-1.html\#: :text=Maharishi\%20Mahesh\%20Yogi\%2C\%20who\%20introduced, headquarters $\% 20 \mathrm{in} \% 20$ Vlodrop $\% 2 \mathrm{C} \% 20$ the $\% 20$ Netherlands.\&amp;text=Steven \%20Yellin\%2C\%20a\%20spokesman\%20for,did\%20not\%20give\%20a\%20cause. 


\section{COLORFUL, WEIRD, AND WONDERFUL * GIANNA ZANZI}

[12.] Michaela, E., \& Orna, S. L. (2015). Fashion conscious consumers, fast fashion and the impact of social media on purchase intention. Academic Journal of Interdisciplinary Studies. https://doi.org/10.5901/ajis.2015.v4n3s1p173

[13.] Miller, J. (2017, August 2). Beatle George Harrison tours the Haight, 1992. San Francisco Chronicle. https://www.sfchronicle.com/entertainment/article/BeatleGeorge-Harrison-tours-the-Haight-1992-11727919.php.

[14.] Newell-Hanson, Alice. Rediscovering radical 70s fashion in San Francisco attics. Vice, 17 Feb. 2017, i-d.vice.com/en_us/article/nennjbrediscovering-radical-70sfashion-in-san-francisco-attics.

[15.] Public Broadcasting Service. (2005). The sixties. Timeline. Text Version. PBS. https://www.pbs.org/opb/thesixties/timeline/timeline_text.html.

[16.] Time Inc. (1970, January 26). Modern living: The psychedelic tie-dye look. Time. http://content.time.com/time/subscriber/article/0,33009,878729,00.html.

[17.] Victoria and Albert Museum. Introducing Mary Quant. V\&A, www.vam.ac.uk/articles/introducing-mary-quant.

[18.] Zimmermann, M. (2013). Rua Augusta and Carnaby Street: The street as a setting for youth sociability in the 1960s. Film, Fashion \& Consumption, 2(3), 247-258. https://doi.org/10.1386/ffc.2.3.247_1 